\title{
MONSTERS AT THE END OF TIME Alternate Hierarchies and Ecological Disasters in Alaya Dawn Johnson's Spirit Binders Novels
}

\author{
Anita Harris Satkunananthan \\ Universiti Kebangsaan Malaysia \\ aharris@ukm.edu.my
}

\begin{abstract}
This paper interrogates the connection between entities that hover in the liminal state between life and death (such as vampires and spirits) and the manner in which these entities relate to Alaya Dawn Johnson's conjurings of alternate political structures and hierarchies in her Spirit Binders series. Johnson's alternate hierarchies are compelling primarily because they are both flawed and liminal. These hierarchies contain gateways between life and death, between material reality and spiritual reality. An ecoGothic lens is applied to these texts as they deal with climate-related disasters and the ways in which the texts instigate not just heroism but also monstrosity. In Gothic fiction, supernatural tropes such as the Vampire, spirits, and intermediaries are often signposts towards psychological states such as Terror and its relation to the Sublime. In Gothic fiction, very often, vampires, spirits and other similar creatures are connected to a hierarchy or community of sorts. A postcolonial Gothic reading of Gothicized texts, however, interrogates the power relations, the sense of haunting underscoring the text as well as the discourse of Terror in relation to the Other. I argue that Johnson's writing enables the reader to peer in between the veils of life and death to unearth the darker sides of human nature, but very often these glimpses are not just about personal choices. These glimpses reveal strategies and missteps that guide the ways in which those hierarchies shape those choices, which Johnson then subverts in her tales.
\end{abstract}

\section{Keywords}

Postcolonial Gothic; futurism; Alaya Dawn Johnson; hierarchies; ecoGothic. 


\section{About the Author}

Anita Harris Satkunananthan is a senior lecturer in Literature (National University of Malaysia), with a $\mathrm{PhD}$ in Postcolonial Gothic Literature (University of Queensland). Her works on Chimamanda Ngozi Adichie and Helen Oyeyemi have been published in Hecate, $3 L$, and in Telling It Slant: Critical Approaches to Helen Oyeyemi (Sussex Academic Press). Her research interests include the Postcolonial Gothic, Postcolonial ecoGothic, Anthropocene literary criticism, Gothic Psychogeography, and Hauntology. Her creative works have been published in Clarkesworld, Strange Horizons, Beneath Ceaseless Skies, and various other publications. 


\section{INTRODUCTION}

Alaya Dawn Johnson's Spirit Binders novels capture the anxieties of an Anthropocene society in relation to climate disasters while foretelling the advent of climate migration. In my opinion, the interplay between the darkness inherent within humanity, civilization, and the natural environment within which haunted edifices and demonic cities are depicted within Racing the Dark (2008) and The Burning City (2010) are inherently Gothic. The novels are particularly Gothic in nature from a postcolonial and ecological perspective and will therefore be analyzed from a postcolonial ecoGothic perspective in this article. Utilizing the postcolonial ecoGothic parameters, this paper interrogates the power relations found in alternate hierarchies as well as the connection between Terror and monstrosity. Johnson's writing enables the reader to peer in between the veils of life and death to unearth the darker sides of human nature, but very often these glimpses are not just about personal choices. These glimpses reveal strategies and missteps which guide the ways in which those hierarchies shape those choices, which Johnson then subverts in her tales. The novels are set in an otherworldly postapocalyptic archipelago, thus setting the stage for a battle royale between the forces of nature and the fractured factions of humanity who form alternate hierarchies after the archipelago was transformed by environmental disaster. The character trajectories in these novels are a result of a sequence of events resulting from these ecological catastrophes that topple the order of their world. By negotiating with the problematics of a primarily and overtly patriarchal culture in the Spirit Binders novels, Alaya Dawn Johnson provides a significantly ecoGothic platform to address issues that may arise in times of environmental disaster which leads to the dismantling of established hierarchies, thereby creating new ones. Within the two Spirit Binders novels, she then allows for solutions that happen within those cultures themselves.

Johnson's novels are intentionally political, and the consequences of human decisions to the environment in her novels are all carefully plotted out. In an interview with Locus Magazine, Johnson says:

To me, the environment in Racing the Dark and The Burning City was something I wanted to be able to discuss. I wanted to use fantasy (that literalization of metaphor) to dramatize some of those conflicts and put it more in the forefront of the reader's mind. (par. 9)

Johnson explains that in traditional fantasy, conflict is driven by evil in a "more didactic guise: evil empires or people" whilst "the wasteland caused by the last war" (as epitomized by J.R.R. Tolkien's "The Scouring of the Shire" in The Return of the King) is usually "turning green and verdant by the end of the last novel" (par. 9). It

Kritika Kultura 33/34 (2019/2020): 526-538 
is clear that politically, Johnson has issues with the traditional ways in which nature or ecology is portrayed in fantasies that take their cue from key Gothic Revival texts by Ann Radcliffe, Horace Walpole, and Matthew Lewis. Johnson reiterates her divergence from this paradigm by noting that in the aforementioned fantasies, environmental destruction is caused by Evil, rather than seen as "the consequences of how you live" (par. 9). It is evident that the "literalization of metaphor" here is very intentional by Johnson as are the consequences of the actions of her promethean protagonists, Lana and Kohaku. Both Lana and Kohaku slowly grow into their monstrous selves as a result of their choices in life-or choices thrust upon them by the fractured hierarchies within which they reside.

In weaving together the attributes of nature and civilization, Johnson undoes the traditional ecoGothic paradigms of nature which have bled over into traditional fantasy fiction by weaving together the attributes of nature and civilization. These paradigms place certain virtues upon nature that herald back to Gothic preoccupations with nature as either a corrupting force (Matthew Lewis) or a force for inspiration (Ann Radcliffe). In so doing, she creates a new paradigm. Her assertions in the Locus Magazine interview are therefore very much in line with my primary interest in interrogating the construction of hierarchies in the Spirit Binders world in relation to education and the economics of the world as connected to an ecocritical perspective. The hierarchies found in Spirit Binders are related to climate change and climate disaster of a supernatural origin, but one might argue that the patterns of climate migration hauntingly echo what is happening in the world today. The paradigm shift as a result of climate change and environmental depredation has been serious enough that the World Bank published a special report about it in 2018. In the report, Kanta Kumari Rigaud et al. assert that mobility is "emerging as the human face of climate change" (1). They note that there has been a growing recognition that "far more people are migrating within their own countries than across borders" (1). In this report, this phenomenon is called "internal migration" (2). There are many kinds of migration arising from climate change in the present day, particularly in lesser developed countries in the Global South. Rigaud et al. note that migration becomes a "common strategy for survival, coping, income diversification, risk management, and adaptation for people facing economic stress and adverse climate conditions" (1). Their analysis of climatebased migration and mobility may be connected to the ways in which Lana's family attempts to adapt to climate change within their own world in Racing the Dark by migrating to other islands (52-55). They move within their own archipelago in order to achieve this, thus setting the stage for tutelage and monstrous transformations that spiral into the events of The Burning City.

In their preface to Ecogothic, Andrew Smith and William Hughes write that issues related to climate change and environmental damage have "helped shape the 
direction and application of ecocritical languages" (5). Smith and Hughes further elucidate that the Gothic as a form is "well placed to capture" these anxieties and that the genre provides "a culturally significant point of contact between literary criticism, ecocritical theory, and political process" (5). The Gothic as a genre may not seem overtly political particularly because of its state of ambiguity, but the postcolonial Gothic certainly is political. This is why I deploy ecoGothic criticism through a postcolonial Gothic lens in this article in order to discern the ways in which Gothic markers in Johnson's text effectively highlight the interchange between characters and their (oft) tragic trajectories into monstrosity. In so doing, Johnson reflects on not just the anxieties of the millennial writer but also upon the general pessimism of a generation in the Spirit Binders novels, which I read as an alternate history of humanity. I see this as a significant authorial choice primarily because the setting of the novels lays bare the psyche of the characters as they grapple with the monstrous choices that they have to make. I connect this monstrosity with Gothic monsters who seem to inhabit these texts whether overtly or within the psyche of these characters.

The fantastic elements of the Spirit Binders novels are analyzed in accordance with postcolonial Gothic parameters applied to the ecoGothic. Postcolonial ecoGothic parameters is a new term I coin in order to investigate Johnson's texts and one for which there is no precedence to date in this specific context. To an extent there is a parallel precedent in Sharae Deckard's explosive discussion on global ecoGothic, expanding from Adrian Ivakhiv's call for a "global-meteorological reading practice" pertaining to the "geopolitical unconscious" (177). Deckard asserts that the literary form can "embed the social-ecological contradictions of capitalism" and as such she offers a "praxis for reading the capitalist world-ecology in Gothic literature" (178). This capitalist view of ecology can be seen in novels in which nature plays a role to augment the thoughts, feelings, and motivations of characters. However, postcolonial paradigms are also important to consider because the patterns of colonial domination and resistance may be seen in both texts. For instance, Tabish Khair writes that the Gothic has a "troubled relationship with the normative in general" (38) and that post-colonial or colonial contexts represent only one of the various negotiations with the normative. But the patterns of colonial domination determine the normative and the non-normative, and often that which is colonized is seen as natural and animalistic. Therefore, the paradigms of the Gothic often are influenced by British exploration and colonization-even the historical parameters tend to see the corrupt and the evil as being somehow part of untamed "nature" as in The Monk, or as some sort of spiritual retreat and solace (despite the dangers) as in the works of Ann Radcliffe.

The literary paradigms of wilderness versus urbanization, monster versus men, or nature as an uplifting force to sustain and nurture humanity, often fail to 
depict the ways in which nature must serve humankind. Concomitantly, nature is very often depicted in the shape of monsters and is therefore Othered. Johnson's texts play with the trope of monsters and make literal the various ways in which nature is used as metaphor and metonymy in so many fantastic and Gothic texts. Monstrosity within the two novels is connected to states of emergency and the struggle for power between cultures and individuals. Fred Botting writes that monsters reflect "the monstrosity of social or familial institutions that constructed them" and therefore "[side] with marginalized and excluded groups" in order to socialize them (172). In Gothic fiction, very often vampires, spirits, and other similar creatures are connected to a hierarchy or community. Johnson's remixing of supernatural hierarchies are compelling primarily because they are both flawed and liminal, containing gateways between life and death, between material reality and spiritual reality. Within the Spirit Binders novels, monstrous transformations herald the crossing between these thresholds of the living and the dead, and are therefore symbolic of the ways in which the interstices of death, life, and monstrosity embody the relationship between humans and nature.

\section{DANCING WITH MONSTERS AT THE END OF HISTORY}

Johnson's speculative writings to date have been set precisely at points in civilization in which normal/material history could have ended and an alternate history and hierarchy could have taken its place. The state of environmental catastrophe found in the Spirit Binders novels feeds into the Gothic tropes of spirit-splitting and a form of vampirism. Johnson juxtaposes these catastrophes against a hybrid cast of characters who have to make difficult personal choices. Nasrin Qader writes of narratives of catastrophe, that they are about a "singular crisis, in time, that is inaugural for each story; but a crisis that primarily disperses itself throughout the narration without interrupting its flow" (7). Qader adds that the narration "comes forth as the aftereffect of this dispersive instant" (7). Qader's thoughtful exegesis on the function of narration to catastrophe may be connected to the manner in which Johnson conceives the changes to hierarchies as a result of catastrophe.

Lisa Kroger writes that the seminal Gothic texts by Walpole and Radcliffe are ecoGothic in different ways (17). For instance, in Walpole's works, outdoor "spaces have a specific purpose for the characters: solace, renewal, protection" while in Radcliffe's work, nature is connected to solitude, liberty, and "the absence of civilisation" (17). As such, Kroger argues, "nature and civilization" are placed in binary opposition to one another" (17). It is clear then that in various Gothic texts, nature is positioned in different ways. Kroger's argument is particularly relevant in pointing out the different ways in which the Gothic Revival authors portray 
nature. Kroger writes that for Radcliffe, the environment is a sort of "conduit of emotions" and that the environment "responds to these characters who reside within its boundaries" (19). However, for Matthew Lewis, nature is very much differentiated from humanity, a "force entirely separate" and a "feral and wild place best left untouched" (20). I find Kroger's reading of Lewis against Radcliffe to be particularly astute because it maps the opposing paradigms of the Gothic Revival in relation to nature. However, in Johnson's texts, both paradigms exist because of Johnson's "literalization of metaphor" and because of the duality of nature as represented in the texts.

Nature in the world of the Spirit Binders plays an active role in corrupting and transforming the characters when they transgress. Sometimes nature actively aids that transgression as may be observed in the influence of fire upon Kohaku and the influence of water and air upon Lana. Nature comes hand in hand with monstrosity in a near-Promethean way, showing us the human figure struggling with and against nature. There is no Frankenstein's creation here but both Lana and Kohaku become the canvas upon which the spirits of the elements cast their mark.

\section{MONSTROSITY AND POWER RELATIONS IN THE SPIRIT BINDERS NOVELS}

The Spirit Binders novels are situated in an "end of times" scenario, and they ask certain questions about the capacity for monstrosity in a post-apocalyptic atmosphere. Johnson's models anticipate the complexities that come with entangled states of being, positing manners in which both protagonists and readers can engage with the ideas of Otherness precisely because that Otherness is at the center of conflict within the two books. Frederic Jameson writes that Gothics are ultimately a class "fantasy (or nightmare) in which the dialectic of privilege and shelter is exercised" (289). Khair references this statement of Jameson to elucidate that this perception is even more applicable in relation to "the colonial/postcolonial axis" primarily because of the "extreme interplay of privilege and power in a colonialist context" (5). Khair's reading of Jameson is particularly helpful in an extrapolation of the postcolonial from the ecoGothic aspects of texts such as Johnson's that seek to liberate themselves from traditional constructions of nature. Monstrosity becomes read as a metaphor then of how power and privilege corrupt and make diseased what seemed incorruptible. It is a parable parallel to what Father Ambrosio experienced in The Monk; it is particularly relevant to Kohaku's ascent to greatness and monstrosity after he becomes the M'oi in Racing the Dark (283). An alternate parallel to the path to power may be seen in Lana's odyssey in both books, as well as Kohaku's indirect search for redemption in The Burning City.

Kritika Kultura 33/34 (2019/2020): 530-538

(C) Ateneo de Manila University

<http://journals.ateneo.edu/ojs/kk/> 
The Spirit Binders novels offer imperfect alternate models of societies in flux and after climate-related apocalypse. These alternate models serve as postulates in projections of how human futures and hierarchies would be transformed and recreated in the face of ecological disaster. In Racing the Dark, the narrative introduces a world on the brink of environmental chaos. The narrative bears witness to the end of an era shortly after the coming of age of Lana, the novel's main protagonist (Johnson 7). Lana's people make their living as divers, prying jewels from the mouth of the mystical mandagah fish (Johnson 10). They have built their society around this economy of islands set within a freshwater sea, which is essential for the survival of the mandagah fish and for the livelihood of Lana's people.

The water around all of these small islands was fresh, not salty. This allowed the mandagah fish to flourish, which in turn made it possible for Lana's people to harvest the jewels and trade them on the main islands. The mandagah, and the fish trade in general, sustained the islanders in these remote regions. (9-10)

The livelihood of her people disappears as the last of the mandagah is eradicated when the freshwater turns salty. The demise of the mandagah is actively foreshadowed in Lana's rite of womanhood in which she crossed the boundaries between life and death by plucking two jewels out of the mouth of a pliant and dying mandagah fish.

She had barely touched it, let alone started the process of prying out the jewel, when its mouth sprang open of its own accord. Her mind went numb. Mandagah fish never willingly surrendered their jewels. Before she could even recover from that surprise, the fish moved its head slightly, and not one but two jewels fell from its mouth and into her palm. (10)

This incident is significant because the only other person, to Lana's knowledge, to have received a jewel that was "orange-red, like the color of the dawn above the surface of the water" was Okilani, an elder of their people (11). Lana had received two jewels because the mandagah fish was dying (11). She hid the jewel that would have marked her as an Elder, but this marks the period in which she begins to receive spectral visitations. These visions start with her grandmother who wished her luck while revealing that she knew Lana's secret: that she had been hiding a jewel that pointed at her secret powers (21). It is apparent here that Lana's transformation into a more monstrous being begins with these visitations. The trajectory of Lana's transformation and growth into powers include a deadly apprenticeship with the witch Akua who has made a powerful pact with the spirit of Death. 
This terrible liminality is to define Lana's existence and is responsible for the Gothic undertones of the books in this series. Shortly after, the protagonist's family is forced to relocate because their island is flooded out after weeks of rain.

Over the next two weeks, the rains pounded the island relentlessly. The ground wasn't visible over most of the island anymore. The men poled barges from house to house, checking on the older people and making sure the supports were sturdy. Even the oldest on the island said that they had never been through a rainy season like this one. Okilani looked grim, and when pressed would say only that the intense rains were part of greater changes to come. (43)

The above passage is a harbinger of the environmental destruction that propels Lana's family into a trajectory of despair, a time of testing that is peculiarly Gothic in its undertones. Her own private fears about her own influence upon the waters of the islands are superstitious but are also a strong foreshadowing of the transformation of the sea and of the weeks of flooding that result in her own climate migration.

The power relations in Racing the Dark is complex and is related to the people who bind and control the elements of Fire, Water, Air, and Earth: the guardians. There are other powers at work in the world of the Spirit Binders. The corruption of the ruling hierarchy of the islands may be discerned in the manner in which Johnson depicts the character of Kohaku. He is an academic who comes to the outer islands to study Lana's people while purportedly teaching their children. Lana observes that "he was here looking for material to make his name in the great Kulanai in Essel" (31). Kohaku tries to persuade Lana, his star pupil, to follow him back to Essel but she does not follow him because she feels tied to her culture and her people. These power relationships are complex and Gothic in structure: the power the island of Essel has over the outlying islands may be read in this fashion, allowing the reader to glimpse the parallels between Jameson's identification of class fantasy and/or nightmare (289). The outer islands are coded as Other, as are the people who ascend outside of the approved paradigms. Even Kohaku, who ascends to M'oi according to tradition, is not a traditional choice for a leader. His lack of power in the case of his sister against Nahe and the power of the Kulanai to discredit him as an academic shows the impact of class structures upon the living (140-142). The near-drunken spree of violence into which Kohaku descends after his elevation also speaks of the ways in which individuals are Othered and rendered monstrous because of a presumed lack of upbringing and class. There are therefore layers upon of layers of coded privilege in these novels, framed by the tensions between the elements and their purveyors. 
Kohaku's relationship with Lana highlights the difference between the more privileged central islands and the islands that Kohaku considers are of "rustic traditions" (33). The powers that the hierarchies possess are supernatural in origin, which is apparent from when Lana reveals that Kohaku had been "telling them about the great Essel wars that lasted for a century after the wind spirit broke free" (33). But these powers may be read as an allegory for the powers that Anthropocene state governments possess which, when misused, can lead to ecological disaster. Lana's conversation with Kohaku is an important foreshadowing, given that Kohaku will later perform a rite of sacrifice that will transform him into the M'oi. The transformation gives him powers and turns him into a spiritual leader, but it makes him insane, becoming a corrupt patriarch whose occultist deal (geas) with the fire spirit leads to the destruction of thousands of lives. It also foreshadows the geas Lana makes with the wind spirit, which turns her into the Black Angel, complete with wings (261). Both Lana and Kohaku are transformed during the course of the Spirit Binders books, thus intimately linking ecological disaster to the monstrous trajectories of their fate, and the eventual loss of their humanity.

\section{FRACTURED SOCIETIES, MONSTROUS TRAJECTORIES}

Racing the Dark is a narrative that intertwines the fates and narratives of Kohaku and Lana: one a former tutor, the other the student. They are briefly romantic enough that Kohaku invites Lana to return with him to Essel. It is an offer Lana refuses because she realizes her fate is tied to her family and her hidden legacy with the mandagah fish. Their paths thus separate.

Kohaku returns to the city-island of Essel where the guilds and the university are situated, and it is also where his own tragic story unfolds. Lana's monstrous trajectory is connected to the fate of her parents after they leave their island home upon Okilani's advice. This is due to further impending environmental disaster in the aftermath of the flooding the islands have experienced (53-54). Since there will be no more mandagah fish, their way of life will therefore change. This is a definite example of climate-based migration. Lana's father, Kapa, moves to Essel to build a life for them as a musician and maker of instruments. Meanwhile, Lana and her mother, Leilani, eke a meager living while they wait. Lana dyes cloth while her mother sells palm-wine. Lana falls ill, thereby causing Leilani to turn reluctantly to the sex trade in order to buy medicine for her daughter. When the money runs out and Leilani is close to despair, the witch Akua strikes a deal with Leilani to enable her to travel to Essel to find her husband. Akua takes Leilani into a dark and troubling apprenticeship that eventually transforms Leilani into a winged being 
who flees for her life while chased by a vengeful Akua, who needs her for her own gambit for power.

Johnson's duology shows different ways in which power corrupts a person but also anchors these transformations firmly in elements and forces of nature that tug and pull at the protagonists through the deployment of power relations. Lana's life is defined by these relationships. The most significant and disturbed power relations in Racing the Dark exist between Lana and the witch Akua (91). The relationship serves as a symbol for the other power relationships in this novel, that of a sepulchral apprenticeship that inducts Lana into discovering her powers and unleashing her own monstrous nature. Following from this, Lana's near-impossible romance with Kai, a water elemental, occurs as she is transitioning into a creature of the air and further complicates the trajectory of her identity and identifications (318-319). Their elemental affiliations trouble their relationship, but it is also a significant relationship that may be connected to the impending catastrophe within the text, another example of how Johnson makes metaphors of nature tangible. One of the most tragic examples of imbalanced power relations leading to rot and tragedy may be gleaned from the death of Kohaku's sister, Emea (135). She dies after having a love affair with Kohaku's academic superior in the Kulanai, which resulted in her being impregnated and subsequently poisoned by him (135). It is this singularly tragic act that leads to the monstrous trajectory of Kohaku's life. As for Lana, her life is defined by the geas (binding) she makes, which results in her being tailed by an avatar of Death. She learns that the witch Akua took her on as an apprentice primarily because she wants to break the binding set upon Death (378), which would naturally have even more of a catastrophic consequence on the islanders. The bleeding into each other between the states of Death and Life, in Johnson's oeuvre, is liminal and inherently political.

The connection between a darker kind of education/tutelage and transformation is further mirrored in the journey Kohaku takes from being a passionate academic to a crazed and powerful despot and in his ultimate search for redemption in The Burning City. His transformation may be seen as the epitome of how troubled power relations in flawed hierarchies can create monsters. The transformation is replete with Gothic tragedy and horror: in The Burning City, the tragic death of Kohaku's sister and her malignant spirit egging him to toe the line between good and evil push him towards this fate. The psychological aspect of Kohaku's relationship with his sister parallels those same torments experienced by Father Ambrosio Matthew in Lewis's The Monk (1794). Khair comments that The Monk relates the story of "an extremely virtuous monk" who has been seduced into committing acts of terror by the Devil," as well as his own "inability to recognise the thin line separating the divine from the demonic" (61). This almost parallels the manner in which Kohaku is transformed from a virtuous man into a monster. There is no other word that 
could fit this one-handed terror who moves through the streets of Essel, one who is capable of killing thousands without remorse (277-283). He is further encouraged by the vision of his dead sister, much in the same way that Lewis's monk is visited by demonic forces in female form (362). In highlighting this internal monstrosity, the narrative brings us closer towards understanding the connection between Gothic terror and representations of the textual Other.

David Punter writes that the forms in which "textual terror occurs will always have an element of the unvarying, as they reflect and represent deep-seated anxieties of birth and death" (240). Birth and death are both liminal events that are fitting metaphors not just for personal anxieties but also Anthropocene anxieties related to the destruction of our natural habitats. These anxieties resemble those felt by Kohaku. The narrative of his monstrous trajectory is thus sandwiched between two pregnancies: the aborted pregnancy of Kohaku's sister and the birth of his daughter (279). Terrified of the monster he has become, his wife removes his daughter away from his presence. She witnesses him arguing with his disembodied sister and is terrified because she sees him "furiously arguing with someone, but of course there was no one else in the room" (270).

Kohaku's home as M'oi is markedly Gothic, a "sprawling labyrinth" with "many hidden things" (269), and this signposts that he has become the Gothic patriarch in the house, an embodiment of both psychological and supernatural terror. Terror is linked to nature in more than one manner as it exemplifies the Burkean Sublime when the self is confronted with a tsunami, a magnificent cataract, or a planetary deluge as a result of global warming.

I cite Punter's arguments for the socio-political reading of Terror because they perfectly exemplify what happens in the monstrous trajectories of Kohaku and Lana. These characters become both monsters and leaders in their own right, created from the corruption and cruelties of the orders which they topple in a time when their world is torn asunder by environmental conflict. As Punter rather successfully avers, terror has "direct connections with the socio-political realm" (244). This lies within the "roots of Gothic fiction in a time of European revolution," thus leading to the French "reign of terror" (244). The reign of terror marked a time in which "terror" was considered as both internal and external. Punter then reiterates that Terror "has the hallmark of a regime" (244). New regimes are born from toppled regimes, as in the case of the French Revolution, and this can be seen in the world of Spirit Binders where Kohaku begins his own "reign of terror" as a M'oi while Lana stalks the islands as an avatar of Death, a figure of deep epistemological terror and embodied power. This is flagged earlier on because the sense of terror connected to the liminal states of birth and death is elevated as Lana, the protagonist, grows into a being who can manipulate the states in between life and death. This was 
foreshadowed in her rite of passage with the mandagah fish: the gift of two jewels signifying both life and death.

In the Spirit Binders novels, Johnson works to incorporate aspects of Polynesian myth and history to create an alternate hierarchy. Hierarchies are present in all of her novels along with a strong undercurrent of terror and tension against competing forces. The various problems connected to abuse of power and people fighting for social justice find an analogue in the rebels' fight against Kohaku in The Burning City. This process is mirrored in Kohaku who becomes bound to the spirit of the destructive volcano, as its Mo'i. His gumption to perform a sacrifice to bind the spirit of the volcano causes the other bindings to loosen, thereby unleashing destruction on the islands that make up the world of the Spirit Binders. Kohaku goes from being an erudite scholar to someone wishing to avenge his sister's death. This desire for revenge along with the power that he gains turns him into another monstrous patriarch and turns his wife Nahoa into an unwilling witness. Terror, as an epitome of the Burkean Sublime, waits in the wings of Johnson's text. It is connected to the crumbling government in Essel, now led by Kohaku, and the formation of new hierarchies in the rebel and counterrevolutionary forces with whom Lana is eventually aligned. Punter accurately observes that in "the work of terror, history and memory are no longer stable; or rather, they are stripped of the illusion of stability and continuity" (240). Because this illusion is stripped, "we find ourselves in a darker world where we can no longer control the boundary between inner and outer" (240). Essentially, terror is an emotion or state of being which is connected to the Sublime and the uncanny. Texts which deploy an awareness of the uncanny challenges the reader to consider the root of hierarchy, for most hierarchies and governments are created out of a consensus to face down some state of exigency.

\section{CONCLUSION}

Racing the Dark and The Burning City are both novels with Gothic tropes containing liminal creatures, spiritual vampirism, difficult power relations, and patriarchal markers, as represented by the Kulanai, Kohaku, and the elders of various cultures. Elements of magic and the supernatural are part of the alternate hierarchy created by Johnson, but in her choices, she has not created a Utopia. Utopias rarely exist successfully for alternate world models although there have been movements towards reclaiming the province of futuristic fiction in more positive ways such as with the solarpunk and hopepunk movements. Johnson's alternate hierarchies lie beyond binaries of positive projections and the negative. Rather, Johnson allows for the scrutiny of imbalances of power that happen within any hierarchy, as is 
evidenced from the progression of Kohaku from being an oppressed academic to a powerful and dangerous despot continuously talking to the ghost of his sister. The narrative grapples with the duality of nature and its impact upon human characters and their choices in the wake of ecological disasters.

The dismantling of hierarchies and the reigns of terror all speak to a different paradigm and view of nature. Nature and the environment in the Spirit Binders novels epitomize all of our Anthropocene anxieties about the fate of our environment. This vision of nature punishes humanity as well as rewards it in a very physical and cogent manner, eliding and destroying the boundaries between civilization and the wild by folding them into one another and creating Promethean monsters at the end of time. I conclude by asserting that the most significant Gothic marker in this tale is that of Otherness in relation to terror, and much of this paper has been concerned with Otherness in relation to character trajectories in the face of environmental disaster-driven conflict. Lana is marked as an Other earlier on in the text but as the narrative progresses the process of becoming Other is clearly delineated. The process is a troubled power dialectic involving the forces that shape the supernatural nature not only of their world but also of their reality and their hierarchies, which I read from a postcolonial ecoGothic perspective. 


\section{Works Cited}

Botting, Fred. Gothic. The New Critical Idiom Series, Routledge, 2014.

Deckard, Sharae. 'Uncanny States': Global EcoGothic and the World-ecology in Rana Dasgupta's Tokyo Cancelled." Ecogothic, edited by Andrew Smith and William Hughes, Manchester UP, 2013, pp. 177-194.

Jameson, Frederic. Postmodernism or, The Cultural Logic of Late Capitalism. Duke UP, 1991.

Johnson, Alaya Dawn. Alaya Dawn Johnson: Dreaming Stories (Interview). Locus Magazine, 2011, http://www.locusmag.com/Perspectives/2011/o3/alaya-dawn-johnsondreaming-stories/. Accessed 11 July 2014.

-. Racing the Dark. Bolden Books, 2008.

--. The Burning City. Bolden Books, 2010.

Khair, Tabish. The Gothic, Postcolonialism and Otherness: Ghosts from Elsewhere. Palgrave Macmillan, 2009.

Kroger, Lisa. "Panic, Paranoia and Pathos: Ecocriticism in the Eighteenth-century Gothic Novel." Ecogothic, edited by Andrew Smith and William Hughes, Manchester UP, 2013, pp. 15-27.

Lewis, Matthew. The Monk: A Romance. Vintage Books, 2009.

Punter, David. "Terror." The Handbook of the Gothic, edited by Marie Mulvey-Roberts, second edition, New York UP, 2009, pp. 243-249.

Qader, Nasrin. Narratives of Catastrophe: Boris Diop, ben Jelloun, Khatibi. Fordham UP, 2009.

Radcliffe, Ann. The Mysteries of Udolpho. Dover, 2004.

Rigaud, Kanta Kumari, Alex de Sherbinin, Bryan Jones, Jonas Bergmann, Viviane Clement, Kayly Ober, Jacob Schewe, Susana Adamo, Brent McCusker, Silke Heuser, and Amelia Midgley. Groundswell: Preparing for Internal Climate Migration. Worldbank, 2018.

Smith, Andrew, and William Hughes, editors. Ecogothic. Manchester UP, 2013.

Speller, Maureen Kincaid. 2011. "Racing the Dark and The Burning City by Alaya

Dawn Johnson.” Strange Horizons, 11 Apr. 2011, http://www.strangehorizons.com/ reviews/2011/o4/racing_the_dark.shtml. Accessed 11 July 2014.

Walpole, Horace. The Castle of Otranto. Penguin, 2001.

Kritika Kultura 33/34 (2019/2020): 538-538

(c) Ateneo de Manila University

<http://journals.ateneo.edu/ojs/kk/> 